\title{
An Analytical Index to the Internet: Dreams of Utopia
}

\section{Carol Casey}

\begin{abstract}
All the current methods of accessing Internet resources fall short when it comes to locating discrete pieces of information and digital objects. One solution to this problem is to create analytical indexes to the Internet. This article explores the need for analytical indexes by looking at current Internet access, traditional bibliographic control, and Web site design. A discussion of some of the issues and problems concerning the development of these indexes, including the design and the resource selection process, emphasizes the impossibility of a comprehensive analytical index to the Internet. The creation of small, focused indexes may be the best solution for accessing specific types of digital information.
\end{abstract}

Perfect bibliographic control would imply a complete record of the existence and location of every book, every document, every article, even every written thought. The probabilities of ever reaching such a utopia are remote. ${ }^{1}$

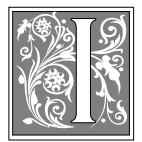

n 1967, Robert B. Downs and Frances B. Jenkins had a vision for information access that is admittedly impossible for a physical collection, but pocket utopias are possible in the digital environment in the form of analytical indexes. Unlike physical materials, digital resources possess properties that make detailed analysis and the ability to access the exact location of these details possible. But, as visitors to the World Wide Web discover, it is a frustrating task to find specific pieces of information or digital objects, despite teasing links that suggest they are only a Web site away. The fact is "the information is at our fin- gertips; we simply lack the ability to get it when and where we need it." ${ }^{2}$

More often than not, "a search for specific data can degenerate into an afternoon of dead ends, blind leads, and false drops, if not outright misinformation." 3 Staff members at Nashville State Tech Library lament that "even when our focus is fairly narrow and we choose our URLs carefully, we probably identify only one site worthy of inclusion for every 10 or more sites visited." ${ }^{\prime 4}$ Add to this long-page downloads, large images, and generally unnecessary plug-ins and special scripts, and finding information on the Web becomes too timeconsuming and inefficient. Too often, the searcher gives up and goes to the library stacks taking two steps at a time. Frequent visitors to the Web conclude that accessing digital information is not "as convenient for random access as a person using a book; turning back and forth between two pages for comparison (once one has found the two pages) is as fast as one cares

Carol Casey is Head of the Catalog Department in Dupre Library at the University of Louisiana at Lafayette; e-mail: casey@mindancer.com. 
to have it, and no command structure and windowing capability stands in the way." ${ }^{\prime 5}$

Just as a library of uncataloged, haphazardly shelved books is of little use when searching for a specific book, the Web will never be a true research tool and resource until a means of directly accessing discrete pieces of information and digital objects is developed. It is clear that "the information highway will not magically sort itself out." ${ }^{\prime 6}$ One solution is to rethink the way the Internet, especially the Web, is currently accessed. Although many directions can be pursued, this discussion focuses on the concept of an analytical index to Internet resources.

\section{Search engine results are often like book index entries without page numbers and with a couple of digital twists.}

A closer look at the current means of access and approaches to bibliographic control is necessary to put the concept of an analytical index into perspective. The most prevalent means of access, if a researcher does not have the address for a specific resource, consists of keyword search engines, hierarchical subject indexes, special indexes, and compilations of links. Each method of access has a place in the digital environment, but none has the focus of even the simplest online library catalog to consistently lead a researcher to relevant resources.

\section{Keyword Search Engines}

Online helpers like keyword search engines such as Altavista (http:// www.altavista.com) are little more than word-spewing spiders that crawl through Web sites weighing the content according to numerical rather than logical measurements. They are "undiscriminating, likely to rank a press release as highly as an investigative news report, and to include everything on a subject no matter how dim or deluded." 7 Limited to reading ASCII text, search engines cannot detect the text found in graphic formats. If sites with graphic-based text do not contain alterna- tive text-only versions or substantial metadata statements, they are all but inaccessible via keyword search engines.

Search engine results are often like book index entries without page numbers and with a couple of digital twists. The keyword is on the page, but where it is and in what context cannot always be determined. It may be tucked into a metadata statement, only visible when viewing the page source. The statement may carry a summary for the entire site, not just the page accessed by the search engine, which increases the chances that the page may not contain the sought-after information. Sometimes the keyword is no longer on the page because search engines only sporadically revisit sites already indexed in the engine's database. If the content of a page is changed or the page is removed from the Web, it may be weeks or months before it is re-indexed. Meanwhile, the engine's database contains all the data for the page compiled by the robot on the last visit to the site.

Keyword search engines are analytical in the worst sense of the concept. They pull individual pages within a Web site out of context. Sometimes the context is completely lost because there are no links to the rest of the site. This happens when Web site designers approach the layout as if the site will always be accessed through the home page first and then relies on visitors to use the browser back button to return to previously viewed pages. Even librarians, focused on a single purpose for a site, occasionally overlook the importance of providing navigational links on each page of the site. Referring to setting up a legislative history Web page for an introductory class on using government documents, Elaine Hoffman stated: "By clicking on a particular title they would automatically link the user to that separate page. By pressing the left arrow key the user could return to the main Web page. In the future I plan to add 'RETURN' buttons to make the functions more apparent." ${ }^{8}$ Disembodied Web pages are similar to random pages ripped from a book and then offered to a reader. 
Grasping the "world wide" part of the World Wide Web is a slow process. Unless mounted on an Intranet, there is no such thing as a strictly local Web site. No matter the purpose of the site, Web designers should work on the premise that search engines are going to crawl through it and pull pages out of context for anyone in the world making the search. Another barrier to finding specific information when using keyword search engines is that "search engine developers have devised different, albeit at times only slightly varied, syntaxes for entering queries." ${ }^{\prime \prime}$ Keywords must be entered in specific ways to get the best-structured search results, and each engine has its own set of search parameters. Unfortunately, patrons "want the information now; they do not want to learn or read anything-they just want to sit down and use the system,"10 so they usually do not make the effort to learn how to use each search engine properly.

Although keyword search engines are capable of bringing the researcher closer to a relevant Internet resource, at best, it is like wandering through a subject area in the library stacks and thumbing through the most promising books. At worst, it is like sorting through the tornout pages of books.

\section{Hierarchical Subject Indexes}

There is little doubt that "it takes human intelligence to compensate for the search engine's limitations and turn technology into a functional research tool."11 Indexes such as Yahoo! (http:/ / www.yahoo.com) are subject guides to Internet resources presented in searchable hierarchical lists. The idea is that the searcher "works down into the hierarchies beginning at the top with the broadest category, and proceeds through the subcategories until arriving, it is hoped, at the goal-the resource that will deliver the sought-after information." 12 More important, the resources are manually selected and analyzed. But there is still a question of quality control "since the people creating many of these subject indexes lack the librarians' training in evaluation and description, mate- rials may be included simply because they fall into the right subject category." ${ }^{\prime 13} \mathrm{Un}$ like keyword search engines, these indexes cannot come close to a global coverage of the Internet so they try to present as high a quality resource as possible.

If a keyword search engine database is comparable to a huge roadside junk shop, subject indexes are online equivalents of comprehensive bookstores. Subject indexes offer something for everyone, but the final decision on the quality and usefulness of the information resource is the responsibility of the visitor.

Yahoo! probably is the best-known and most emulated hierarchical subject index. The information about each resource in the Yahoo! database is collected and cataloged by humans rather than machines and is presented in a neat, uniform display, echoing bibliographic records. Just as a keyword search of an online library catalog reaches the different parts of a bibliographic record, a keyword search of the Yahoo! database encompasses the Web site title, the prepared commentary for the title, a list of keywords, and the URL.

Unlike keyword search engine results, subject index hit lists point to the whole Web site rather than a page from it. Because of this, subject indexes suffer from the same lack of accessibility depth found in many library online catalogs. In libraries, the main unit of bibliographic currency is the package containing the intellectual work or works, and this concept is transferred to Internet resources. Just as a collection of books arranged by subject is an improvement over a warehouse of unsorted books, subject indexes are a better choice than keyword search engines for quickly locating a Web site on a specific subject.

\section{Special Indexes and Compilation of Links}

Some special indexes, many compiled by librarians, offer Internet resources in an organized format, usually by subject. What sets these apart from an index such as Yahoo! is that the content of the resources is evaluated for quality and accuracy. An ef- 
fort is made to choose Internet resources following the same criteria used to select other materials for the library collection because "collection development is just as important for electronic resources as for print-perhaps even more so, because of the difficulty of locating resources on the Internet or the Web."14

Because they are not commercially driven, most of these indexes are known primarily to the intellectual community they serve and to a percentage of visitors who discover them while searching the Internet. A well-established, value-added index compiled by librarians is The Internet Scout Project (http://www.scout.cs.wisc.edu/scout/report/). This ambitious project tries to provide "Internet users, particularly those in higher education, with current, selective, and well-annotated pointers to the best that the Internet has to offer." ${ }^{\prime 15}$ Most of this work is performed by professional librarians and subject experts, and the resources are cataloged using Library of Congress Subject Heads and Classification, plus Dublin Core elements. They are archived at The Scout Report Signpost (http:/ / www.signpost.org/ signpost/index.html) for quick access.

If hierarchical subject indexes such as Yahoo! are like bookstores, these valueadded resource guides are close relatives of a library collection. The emphasis is still on the Web site as the basic unit of information packaging, but because the evaluator has the opportunity to examine the site first, the quality and accuracy of these resources have the potential of being uniformly higher than the quality and accuracy in a library collection. Most library materials are selected sight unseen through blanket orders or based on reviews and recommendations.

The compilation of favorite or related links seems to have become a part of general Web site design. Because creating links is so easy to do, there is a certain lack of discrimination when linking to a site. Even on library Web sites "there is a strong tendency to want to include links to as many remote resources in one's Web collection as possible."16 Some of these collections of links are of high quality, others are compiled haphazardly. Although a nice simple compilation of links on a specific topic (much like a subject bibliography) can be an extremely valuable resource, it is important to remember that "it only takes one casual link from a reputable site to lead into a morass of meaningless sites."17

The curators of The Internet Scout Project understand that "fruitful information retrieval requires repositories of organized collections of information with indexing systems that ensure efficient retrieval."18 Although these types of indexes come closer to this goal than keyword search engines and hierarchical subject headings, the nature of Web sites themselves presents the greatest barrier to access.

\section{Thumbing through Web Sites}

Before the development of the graphical user interface (GUI), Internet resources were text files. This format worked well as long as graphics and sounds were not needed to illustrate the text. Because humans communicate and create in an assortment of visual and aural mediums, many of the ASCII-based Internet resources were limited and had to be supplemented by physical materials.

The early Internet was never a threat to the book as a comparable, or even superior, form of presenting information. The Web may rival physical formats someday, but not until visitors have equal access to the optimal technology to handle the endless creative Web design and layout. Even then, the proper technology cannot overcome all the access problems because searching the Internet is still "a complicated job of sifting through massive amounts of information to find the few valuable nuggets." 19 Theoretically, it does not sound much different from thumbing through a range of library books. If a hit list is comparable to a range of books, the ratio between relevant and nonrelevant sites depends on how the Internet is searched. Books on library shelves are placed according to a logical, usually subject-based classification scheme. Keyword searches, even in hierarchical or special indexes cannot 
guarantee any logic or even relevancy in on-the-spot compilations of links.

Problems with access are not gone after a promising Internet resource is found. With specific information goals in mind, researchers often want to take only a quick peek at a page. Books allow readers the luxury of flipping between a page of text and a color photographic plate without waiting for various elements to load and reload into a browser. Browsing aids in books such as indexes and detailed tables of contents leads to pages containing the words or concepts the researcher is seeking, saving the effort of skimming every page.

Web sites, on the other hand, are generally not designed for quick glances or thumbing through for an overview. The unique "new qualities of the Web-graphics, sound, animation, and digitizationmake it an exciting, revolutionary medium, but it is also ever-changing, chaotic and unorganized. ${ }^{\prime 20}$ Most Web sites do not have detailed indexes that point to specific text, images, or sounds. This means that "the researcher is always looking at information through blinders, one Web page at a time. It's fairly easy to get confused and off track if webmasters have not constructed their pages well." ${ }^{\prime 21}$ Visitors may have to wait while images, long-text passages, tables, and various plug-ins and scripts load into the browser just to take a quick peek at a page. Often more time is spent watching pages download than actually finding the needed information.

Because of the lack of logical layout in site design, the Web "was not designed to support the organized publication and retrieval of information, as libraries are."22 Many Web site designers see the site only in terms of itself or the purpose for which it was created and forget that keyword search engines dissect sites and present bits and pieces of them in search results. Although a "common practice" is evolving for Web sites, there are still many older sites and sites created by newcomers to the Web who inevitably make the same design errors. Until technology allows for quick access to all Web pages regardless of content and design, an alternative to the current holistic approach to Internet resources is the only way to isolate information so visitors can access it quickly.

Just as it is possible to compile satisfactory subject indexes to the Internet, an analytical index can be achieved. If The Scout Report Signpost is a close relative of a library collection, the analytical index resembles an encyclopedia. Because "users suffer less from lack of information than they do from information overload," an encyclopedic approach may be of greater use for basic information needs. ${ }^{23}$

\section{Cataloging's Stepchild}

The best cataloging is a compromise somewhere between just putting books on shelves and reproducing the complete text in an indexed form as some hope to do in a online environment. $^{24}$

Generally speaking, to access information from a book, the whole book must be in hand. This is not true for a Web site. Thus, "the bibliographic structure that guides researchers to the location of information in the print world simply has no analogy in the digital realm." 25 To utilize the unique characteristics of a Web site, the efforts made in subject and special indexes must be taken to the next level: locating and organizing the contents of these sites.

\section{Anything that goes beyond the essentials of just getting the materi- als on the shelf is not worth the time and resources.}

The analytic has always been the stepchild in the world of bibliographic control. In the ideal, traditional analytic catalog, "a record is made for every item, also for every document in multi-document items, and for every work." ${ }^{26}$ Analytics also can include elements such as book chapters, audio tracks, and art portfolio leaves. Unfortunately, the bibliographic record representing a single title, series, or serial is 
the most common unit in library information access, and providing access to multiple works within these packages is a luxury that libraries selectively indulge in.

Analytics in card and online catalogs have always been problematic. According to Herbert H. Hoffman, "leaving the periodical literature aside, a library of 100,000 items might contain half a million works that are not easily accessible to patrons searching the online cata$\log .{ }^{\prime 27}$ The ability to access these hidden resources has never been fully tapped because bibliographic control has a long history of being considered a costly necessary evil for libraries. Anything that goes beyond the essentials of just getting the materials on the shelf is not worth the time and resources. Efforts to add access to inaccessible parts of a collection are often determined by factors beyond the cataloger's control. Janet Swan Hill asserted that "if the sheer bulk of cards to be filed ... led to the development of arbitrary limitations to the number of names and subjects that would be traced for any one title, imagine how easy is was to reject any other practice-such as ... cataloging the internal contents of works." ${ }^{28}$ To fill the void, indexes and other types of reference works are compiled to provide access to some types of materials such as monographic sets, series, and works on micro formats, but these resources are only useful if patrons know they exist and how to use them.

Accessibility did not greatly improve with early online systems, which were little more than automated card catalogs. In a May 1994 message posted to the AUTOCAT Listserv, Anaclare Evans stated: "The elegance of the linking fields and analytic records which MARC provides is contrasted by the inelegance of some local systems in handling these records." ${ }^{29}$ When keyword searching was enabled in online catalogs, enhanced tables of contents became a popular selling point among bibliographic record vendors and help provide access to works within works. Even with this increased accessi- bility, patrons still have to access the whole package to get to the parts because of the rigid characteristics of physical formats.

It is interesting that Hoffman's 1998 study of the different types of analytics in a library online catalog concluded that "a search for a specific work will:

1. Retrieve all manifestations of that work,

2. Retrieve only that work, without false drops

3. Not require a second pass, and

4. Clearly collocate all retrieved work titles." 30

These characteristics are what most people expect when searching the Internet. Unfortunately, the unfathomable size of the Internet, the uneven content, and the lack of optimal means to access discrete information make this impossible. In fact, it is reasonable to believe that "while there may have once been a common body of rules to govern the creation of catalogs, there is not, and is never likely to be, such a body of rules to govern the organization of the wide range of information available in electronic form." ${ }^{31}$ The methods of access must be as on-the-fly as digital materials themselves and flexible enough to stay usable even as the digital environment evolves.

\section{Rethinking Bibliographic Control}

We must ask ourselves what we want to see in the future of cataloging and what the acceptable norm of organization for the electronic world is if not cataloging as usual. ${ }^{32}$

Because Web sites are not like books, it is reasonable to believe that traditional approaches to bibliographic control need to be reevaluated for Internet resources. This is especially true when attempting a greater level of accessibility. Traditional cataloging is about creating a representation of physical objects in a standardized, concise manner that can be easily indexed in different ways. Catalog cards are distillations of physical objects, plus a location device, usually in the form of a call or accession number. Because cards cannot hop 
out of the drawer and lead patrons to the physical object, patrons must understand how to use the location device. Although there is much discussion on the unstable nature of the Web, there is probably as much chance of a Web site being at the other end of a link as finding a book on the shelf where its supposed to be.

If a Web site is treated as a complete entity like a book, consistently structured bibliographic records are a workable form of access with the added advantage that the location device points directly to the resource. Unlike physical materials, the indexer or cataloger is not restricted to pointing to the whole Web site in order to access a specific part of it. If the analytics are carefully chosen and the necessary context is described as needed, accessing the whole Web site is less important than taking the researcher directly to the informational goal. If the same kind of analytic indexing is applied to a physical collection, the context remains important only because the researcher must access the larger package before the soughtafter information can be obtained.

In-depth summaries and descriptions are unnecessary when pointing to a digital object or a single piece of information. If the analytic points to a photograph of gray whales, the encyclopedic approach is to devise as many subject keywords that will lead patrons to the resource. It is just as quick for researchers to click on the link and go straight to the photograph as it is to read a description or summary of the entry first. This is the main difference between finding physical objects and digital objects. Because physical objects involve the step of having to locate the materials, a clear description of the resource is necessary to ensure that is it worth further investigation. In the digital environment, the resource is just a link away and researchers have the luxury of flipping through potentially relevant Web pages. Elements from formats such as the Dublin Core Metadata Set should be provided with the entry, especially descriptions of the overall Web sites and warnings about elements that may cause download or access prob- lems. In general, the subject keywords usually provide enough information for visitors to decide whether the resource is relevant to their information needs.

Another major difference between physical and digital materials is that catalogers are restricted to creating a single, logical classification to place physical materials in a specific physical location. Web sites are already "shelved" in cyberspace, and because a link to a URL can be labeled with text or graphics, there are no limitations to the number of different index entries pointing to a single URL.

\section{Like an encyclopedia, an analytical index should be a combination of a place to find quick, concise answers or digital objects and a jumping-off point for continued research.}

The bibliographic information for digital analytics must be flexible enough for variable Web site designs and content presentations. Creating full Dublin Core Metadata statements is appealing to catalogers used to working with cataloging standards, but the effort made for a book that will survive for hundreds of years is not worth it for a Web site that may not last a year and is running on technology that will quickly fade into obsolescence. Unlike books, "reading and understanding information in digital form requires equipment and software, both of which are changing constantly and may disappear completely from the market within a few years' time." 33

In rethinking bibliographic control for digital materials, the main unique factor to remember is that the bibliographic information runs on the same technology and in the same formats as the resources it accesses. Not only is the bibliographic information seamlessly linked to the rest of the Web, it is prone to the same instability as all the Internet resources. On the other hand, if an effort is made to capture the resources for an Intranet or permanent storage, the means of access also can be captured. Through "emulation of technical environment- the use of systems 
which run in a new operating environment, but emulate (simulate) a previous, now obsolete environment," the resources can be accessed and studied without having to re-catalog them. ${ }^{34}$ This idea of portability is very much in the spirit of an encyclopedia.

\section{An Analytical Index}

One of the ironies of an analytical index to the Internet is that the best format for the index is a Web site. The design of this Web site can have an impact on the usefulness and usability of the index. Factors such as ease of use, clear navigation, and straightforward instructions are not only important for patrons, but also for whoever maintains the site. Because it takes so much time and effort to find appropriate Internet resources and prepare the appropriate bibliographic access, a simple mechanism for quickly adding, changing, and deleting entries should be the centerpiece of the index. Various levels of interaction with visitors also can enhance the site. These features can range from simple e-mail forms for reporting problems and suggesting resources to allowing visitors to fully customize and personalize pages for compiling favorite links or saving search sets. The most effective index will remain dynamic and change as Internet resources and the supporting technology change and grow.

Probably the most difficult part of compiling an index of this type is selecting the resources. Theoretically, nearly all Web sites contain something that a visitor to an analytical index may be searching for. Besides being an impossible task to sift through one Web site at a time gleaning every discrete bit of information and digital object, an attempt at complete comprehensiveness undermines the immediate need for such a resource. Like an encyclopedia, an analytical index should be a combination of a place to find quick, concise answers or digital objects and a jumping-off point for continued research.

The difference in the way that printed encyclopedias are compiled and an analytical index to Internet resources is approached can be an impediment to find- ing the desired depth of information coverage. The information in encyclopedia entries comes from subject experts and printed sources in the fields covered. It is consolidated into concise, comprehensive presentations, often with accompanying bibliographies. Indexers of the Internet are collecting, not compiling the entries. This leaves researchers at the mercy of how the author of the Web site approaches a subject, unless the analytical index includes ways of linking related resources together and even enhancing each resource with added information. Instead of being daunted by the effort to add these extra values, it is important to keep in mind that "packaging and repackaging information for the usefulness of our many and varied publics has long been the forte of librarians and a specialty of librarianship." ${ }^{\prime 35}$

Selecting resources within the context of the Web is impossible because the digital environment is too vast to get even an overview of its resources. Although experts in different fields can be used to locate and evaluate potential index entries, this lack of overview makes it impossible to put the found information into perspective. Even the effort to keep up with new Internet resources is difficult to maintain, and "many of the librarian-created projects contain redundant resources, just as efforts by many libraries to establish links from their Web sites contain a similar core set of sites." ${ }^{\prime 36}$

Imagine being let loose in the world's most comprehensive bookstore and receiving instructions to collect and organize all the materials on all the disciplines covered in its collection development policy. The amount of material is overwhelming, as is the realization that it is impossible to gather, catalog, process, and house everything. Even a decision to choose only the "best" or most comprehensive resources does not make the task easier because it is impossible to look through all the resources before engaging in the selection process. Each choice is made based on the quality of the material itself and its relation to all the materials evaluated before it. It is a slow, inefficient process because many items will be 
reevaluated, chosen, and removed from the collection, possibly many times before all the materials are sorted.

If the task of finding the highest-quality resource when all the choices are physically present is arduous, trying to grope blindly through invisible-until-retrieved Internet resources is impossible. The best an indexer can do is to evaluate each resource as it is found and not worry that six other, equally good resources in the index contain the same image or piece of information while other aspects of a subject are not covered at all. The question is whether to spend too much time deciding whether to include a resource or simply to add it to the index and spend the time looking for more resources. In an environment as unstable as the Internet, the redundant resources may be pulled from the Web within a week and a half dozen resources on other aspects of the subject may just as suddenly pop up. The question of context is just as much a problem for a Web site in the digital universe as for a Web page in a Web site, except that there is no way to put the Web site completely into context.

Some aspects of the indexing can be automated. For instance, URLs can be automatically added to existing subject keyword lists, providing instant access. This can even be done at the same time that the resource is found by simply cutting and pasting the URL into an online form available to the indexer. Moreover, other elements can be included simultaneously in the description of the resource. Unlike physical materials, there is no time lapse between cataloging and shelving. As soon as the resource is submitted to the analytic index database, it is available to the visitor. Conversely, if the content of the resource changes or is removed from the Internet, the information can be deleted from the index as soon as any problems or changes are discovered.

It is unlikely that an analytical index can be fully automated because "documents on the Web are not structured so that programs can reliably extract the routine information that a human indexer might find through a cursory inspection. Furthermore, the professional indexer can describe the components of individual pages of all sorts (from text to video) and can clarify how those parts fit together into a database of information." ${ }^{17}$ The best solution is to find the perfect balance between humans and technology.

\section{Pocket Utopias}

The Internet, and the technology it runs on, is not going to remain suspended in time, waiting for librarians to devise a sensible means of organizing and accessing the resources available on it. Libraries and librarians have to be as dynamic and flexible as the Internet in order to utilize it in a way that is truly beneficial to patrons. Current methods of access to Internet resources have come a long way from "slow modems, pokey CPUs, arcane UNIX commands, perverse communications protocols, obscure ftp sites, a text-based interface and similar obstacles, ${ }^{\prime 38}$ but they have not brought access to a consistent level that we expect from basic online library catalogs. Approaching the resources from an analytical viewpoint has the potential of increasing the quality of access for certain types of information and digital objects because "as users are confronted with greater volumes of content, the maxim 'less is more' is increasingly applicable." ${ }^{\prime 39}$

\section{Notes}

1. Robert B. Downs and Frances B. Jenkins, ed., Bibliography: Current State and Future Trends (Urbana, Ill.: Univ. of Illinois Pr., 1967).

2. Nick Gall, "Information Everywhere and Not a Drop to Drink," Network Computing 9 (Apr. 1, 1998): 99.

3. Steven R. Harris, "Webliography: The Process of Building Internet Subject Access," in Acquisitions and Collection Development in the Humanities, ed. Irene Owens (New York: Haworth Pr., 1997), 30.

4. James R. Veatch, "Insourcing the Web," American Libraries 30 (Jan. 1999): 64-67.

5. Peter Suber, "The Database Paradox: Unlimited Information and the False Blessing of 
'Objectivity,'” Library Hi Tech 10, no. 4 (1992): 51-57.

6. Samuel Demas, Peter McDonald, and Gregory Lawrence, "The Internet and Collection Development: Mainstreaming Selection of Internet Resources," Library Resources E Technical Services 39 (July 1995): 275-90.

7. “The Total Librarian," Economist 340 (Sept. 14, 1996): 12.

8. Elaine Hoffman, "Untangling the Web of Legislative Histories: A Web Page for Bibliographic Instruction on the Legislative Process," in The Challenge of Internet Literacy: The Instruction-Web Convergence, ed. Lyn Elizabeth M. Martin (New York: Haworth Pr., 1997), 120.

9. Nicholas G. Tomaiuolo and Joan G. Packer, "An Analysis of Internet Search Engines: Assessment of over 200 Search Queries," Computers in Libraries 16 (June 1996): 58-62.

10. Verlene J. Harrington, "Way Beyond BI: A Look to the Future," Journal of Academic Librarianship 24 (Sept. 1998): 381-86.

11. Mary Y. Chau, "Finding Order in a Chaotic World: A Model for Organized Research Using the World Wide Web," in The Challenge of Internet Literacy: The Instruction-Web Convergence, ed. Lyn Elizabeth M. Martin (New York: Haworth Pr., 1997), 38.

12. David G. Dodd, "Grass-Roots Cataloging and Classification: Food for Thought from World Wide Web Subject-Oriented Hierarchical Lists," Library Resources E Technical Services 40 (July 1996): 275-86.

13. Harris, "Webliography."

14. Susan K. Martin and Don L. Bosseau, "Organizing Collections with the Internet: A Vision for Access," Journal of Academic Librarianship 22 (July 1996): 291-92.

15. Susan Calcari, "The Internet Scout Project," Library Hi Tech 15, no. 3-4 (1997): 11-18.

16. Stephen E. Toub, "Adding Value to Internet Collections," Library Hi Tech 15 (1997): 148-54.

17. Walt Crawford, "The Card Catalog and Other Digital Controversies," American Libraries 30 (Jan. 1999): 53-58.

18. David P. Goding, "The More Things Change, the More They Stay the Same: The Future of the Library and the Library Profession," in Collection Development: Access in the Virtual Library, ed. Maureen Pastine (New York: Haworth Pr., 1997), 19.

19. Deanna B. Marcum, "Digital Libraries: For Whom? For What?" Journal of Academic Librarianship 23 (Mar. 1997): 81-84.

20. Judith M. Arnold and Elaine Anderson Jayne, "Dangling by a Slender Thread: The Lessons and Implications of Teaching the World Wide Web to Freshmen," Journal of Academic Librarianship 24 (Jan. 1998): 43-52.

21. Goding, "The More Things Change, the More They Stay the Same."

22. Clifford Lynch, "Searching the Internet," Scientific American 276 (Mar. 1997): 52-56.

23. Marcum, "Digital Libraries."

24. Heather S. Miller, "The Little Locksmith: A Cautionary Tale for the Electronic Age," Journal of Academic Librarianship 23 (Mar. 1997): 100-107.

25. Eileen Hitchingham, "Collection Management in Light of Electronic Publishing," Information Technology and Libraries 15 (Mar. 1996): 38-41.

26. Herbert H. Hoffman and Jeruel L. Magner, "Future Outlook: Better Retrieval through Analytic Catalogs," Journal of Academic Librarianship 11 (July 1985): 151-53.

27. Herbert H. Hoffman, "Evaluation of Three Record Types for Component Works in Analytic Online Catalogs," Library Resources E Technical Services 42 (Oct. 1998): 292-303.

28. Janet Swan Hill, "The Elephant in the Catalog: Cataloging Animals You Can't See or Touch," Cataloging $\mathcal{E}$ Classification Quarterly 23, no. 1 (1996): 5-25.

29. Anaclare Evans (1994, May 23). Re: Table of Contents. AUTOCAT [Online]. Available email: listserv@listserv.acsu.buffalo.edu/Getpost autocat 16384 [1999, March 8].

30. Hoffman, "Evaluation of Three Record Types for Component Works in Analytic Online Catalogs."

31. Norman D. Stevens, "Looking Back at Looking Ahead, or 'The Catalog of the Future Revisited' with Additional Speculation," Information Technology and Libraries 17 (Dec. 1998): 188-90.

32. Ling Hewy Jeng, "A Converging Vision of Cataloging in the Electronic World," Information Technology and Libraries 15 (Dec. 1995): 222-30.

33. Deanna B. Marcum, "The Preservation of Digital Information," Journal of Academic Librarianship 22 (Nov. 1996): 451-54.

34. Ibid.

35. Paige G. Andrew and Linda R. Musser, "Collaborative Design of World Wide Web Pages: A Case Study," Information Technology and Libraries 16 (Mar. 1997): 34-38.

36. Norman Oder, "Cataloging the Net: Can We Do It?" Library Journal 123 (Oct. 1, 1998): 47-51.

37. Lynch, "Searching the Internet."

38. Goding, "The More Things Change, the More They Stay the Same."

39. Toub, "Adding Value to Internet Collections." 